\title{
Portfolio selection using ELECTRE III: Evidence from Tehran Stock Exchange
}

\author{
Aazam Shabani Vezmelai ${ }^{a^{*}}$, Zahra Lashgari ${ }^{\mathbf{b}}$ and Amirreza Keyghobadi
}

${ }^{a}$ Master of Accounting, Department of Accounting, Economic and Accounting Faculty, Central Tehran Branch, Islamic Azad University, Tehran, Iran ${ }^{b}$ Assistant Professor, Department of Accounting, Economic and Accounting Faculty, Central Tehran Branch, Islamic Azad University, Tehran, Iran

\section{H R O N I C L E}

Article history:

Received July 10, 2014

Accepted November 17, 2014

Available online

November 182014

Keywords:

Decision Making Criteria

Portfolio Selection

Multiple Criteria Decision Making

ELECTRE III

\begin{abstract}
A B S T R A C T
Ranking the companies can be a useful guide for investors to select an optimum portfolio. Tehran stock exchange (TSE) uses liquidity criterion to rank the companies; however, this study shows that preferences of investors, the criteria they use to evaluate companies' performances, and the extent to which ranking of companies based on investors' criteria are in line with the ranking announced by the stock exchange. Since the criteria used for ranking the companies are various and often conflicting and because each multiple criteria technique has its own specific characteristics, various rankings are offered. Therefore, it is required to utilize multiple criteria decision making models to avoid confusion of investors. For this purpose, some companies were selected from 50 top companies listed in 2011 in TSE, which maintained the reliability of their ranks and finally, 20 companies were selected and were ranked based on investors' criteria using EECTRE III Technique. The obtained ranking was then compared with the ranking offered by stock exchange. Research results indicate that ELECTRE III technique was a useful and efficient method to select a portfolio. Moreover, valuebased criteria as well as accounting criteria are suitable and useful bases for investors to select a portfolio.
\end{abstract}

\section{Introduction}

There are some evidences in portfolio optimization that investors prefer portfolios that lie behind the non-dominated frontier of the Markowitz model even though they are dominated by other portfolios with respect to two criteria; namely expected return and risk. This observation can be explained by the fact that not all the relevant information for an investment decision can be captured in terms of explicit return and risk (Hallerbach \& Spronk, 1997). By considering additional and/or alternative decision criteria, a portfolio dominated with respect to expected return and risk may make up for the deficit in these two criteria by a very good performance in one or several other criteria and thus be non-dominated in a multi-criteria setting. Moreover, investors may differ substantially in their perception of the relative importance of various attributes (Ehrgott et al., 2004).

\footnotetext{
* Corresponding author

E-mail address: shabani vezmelai@yahoo.com (A. Shabani Vezmelai)

(C) 2015 Growing Science Ltd. All rights reserved.

doi: $10.5267 /$ j.ds1.2014.11.003
} 
An investor usually considers several factors when selecting a portfolio. In this research, some criteria are simultaneously implemented to evaluate performance and to rank companies in order to select the portfolio, which best meets the investors' objectives and preferences. Decision making by including several criteria each with a special position will become possible only by utilizing Multiple Criteria Decision Making (MCDM) models. An investor will be able to achieve a specified return with a lower risk by using the best investment model. In other words, accurate management of assets is the consequence of correct use of portfolio optimization models. MCDM is a group of methods or techniques that help decision makers aggregate several criteria in order to evaluate a set of predefined alternatives (Zopounidis et al., 1999). MCDM models are also strong means for analyzing decision making problems with various conflicting criteria. As a branch of MCDM models, outranking models deal with a more accurate and actual modelling of decision making problems by assisting in definition of outranking relations and based on paired comparisons. Strict preference relations include weak preference, indifference and incomparability are defined by preference thresholds $(p)$, indifference thresholds $(q)$ and Veto thresholds ( $v$ ) (Figueira et al., 2005). ELECTRE I was proposed by Roy and Vanderpooten (1996) and later, some changes were made to this technique which included ELECTRE IV (improvement of ELECTRE I by providing veto threshold), ELECTRE IS (modelling of problems with incomplete data), ELECTRE II (ranking the alternatives by strict and weak preferences), ELECTRE III (ranking the alternatives using Pseudo criteria and fuzzy outranking relations), ELECTRE IV (ranking of alternatives without any need to weighing the criteria) and ELECTRE TRI (allocating the alternatives to predefined classes) (Figueira et al., 2005).The methods from the ELECTRE family are very popular and they have been used with success in a great number of studies and in portfolio selection by Martel et al. (1988), Szala (1990), Khoury et al. (1993), Hurson and Zopounidis (1997), Zopounidis et al. (1995).

Performance evaluation criteria are major components of performance evaluation systems of companies and management control. Suitable planning and control-based decisions require awareness of performance of the units. Evaluation of performance of organizational units is a prerequisite for allocation of limited organizational resources and comparisons between anticipated and actual amounts is a guide to future allocations. Financial criteria of performance evaluation are divided into two groups; namely value-based criteria (modern criteria) and accounting models-based criteria (financial and traditional criteria). In economic models, company value is a function of profitability, existing priorities, potential investments, and balance between return and cost of capital. However, in accounting-based criteria, it is the financial in which the reported profit is of a great importance to the users. The difference between value-based criteria and traditional (accounting) criteria is that in value-based criteria efforts are made to address all financing costs. Researchers such as Stewart (1993), Bausch et al. (2003), Bacidore et al. (1997), Lehn and Makhija (1996), Lipe (1998), Balsam and Lipka (1998), Chen and Dodd (2001), Worthington and West (2004), Shim et al. (2006), WenShiung Lee et al. (2009), Lee et al. (2011), etc. have conducted researches to find the best performance evaluation criteria.

The present research is conducted in parallel with finding the main criteria for evaluating companies' performances from the viewpoint of investors and to understand the role of ELECTRE III as an MCDM technique in selecting a portfolio in Tehran Stock Exchange Market.

\section{Methodology}

Investors in the market always seek to obtain high profits. They buy shares, which appear the best shares and can provide them with the highest profit and return. The fact that how much the activities of managers are in line with shareholders' demands and their profit and how much they have been successful in providing asset and value for shareholders are determined through performance evaluation system. In order to identify investors' preferences, 6 criteria were identified through distribution of Delfi questionnaire among experts. In the next stage, the degree of importance of 
criteria was identified by using another questionnaire with Likert 5 scale test. The identified performance evaluation criteria are as follows,

(1) Economic Value Added (EVA) including value-based criteria; (2) Return on equities (ROE); (3) Return on assets (ROA); (4) Q-Tobin; (5) Earning per share (EPS); (6) Price/Earnings per Share (P/E) from among accounting criteria. EVA is a criterion used for a general supervision in the field of creating value for company. This criterion is equal to the profit obtained after deducting all costs including cost of capital (Stewart, 1991). Since investors anticipate to receive rewards against providing financial resources and bearing business risk, operational profit of company should exceed capital cost in order to create values for shareholders. This issue constitutes the infrastructural philosophy of EVA (Bacidore et al., 1997).

$\mathrm{EVA}=\mathrm{NOPAT}-\% \mathrm{C}(\mathrm{TC})$

Here, NOPAT is the net operational profit after tax deduction, $C \%$ is the rate of capital cost (\%) and $T C$ is the general utilized capital cost.

$\mathrm{P} / \mathrm{E}$ is the ratio of market price for a share divided by the profit of the same share. It indicates the amounts, which should be paid by investors for per rate of profit.

EPS includes revenue in lieu of each share (Johnson et al., 2003).

Q-Tobin is calculated by dividing company's market value by book value or the value of substitution of company assets. High Q-Tobin ratio usually indicates the value of growth opportunities for company (Johnson \& Soenen, 2003).

ROA is the net profit plus interest cost against total assets. In fact, it is the utilization ratio of assets, which shows how efficient and effective a company uses its own assets (Johnson \& Soenen, 2003).

ROE is the net profit arising from each salary unit of ordinary shareholders (Johnson et al., 2003).

Tehran Stock Exchange (TSE) announces the list of 50 most active companies in the stock exchange on a quarterly basis. Top companies in TSE are identified based on a combination of share liquidity and effect on companies in the market and within the framework of the three following criteria, namely:

(a) Traded shares in transaction hall including the number and value of traded shares, frequency of shares transactions, and number of days and trades;

(b) Effect of company on the market by considering average issued shares;

(c) Average current value of company shares within the period under study. This study covers the companies selected from the 50 top TSE companies in 2011, which remained in the list within the four 3-month periods. In other words, they maintained their reliability. On this basis, 20 companies were selected as statistical population.

\subsection{ELECTRE III Technique (Elimination and Choice Translating Reality Technique)}

ELECTRE III was designed to improve ELECTRE II and thus deals with inaccurate, imprecise, uncertain or ill-determination of data. This purpose was actually achieved, and ELECTRE III was applied with success during the last two decades on a broad range of real-life applications. In the current description of ELECTRE III, we will omit several formulae details. The novelty of this 
method is the introduction of pseudo-criteria instead of true-criteria. In ELECTRE III the outranking relation can be interpreted as a fuzzy relation (Figueira \& Roy, 2002). ELECTRE III requires an input of criteria evaluations for the alternatives, called decision matrix, preference information, expressed as weights, thresholds, and other parameters. The alternatives' performances can usually be determined with "certain accuracy" and the imperfect knowledge about the evaluations can be taken into account when defining the thresholds for the model (Montazer et al, 2009).

The ELECTRE III method is based on two phases. First, the outranking relation between pairs of actions is formed, which is in an outranking matrix. The second phase consists of exploiting this relation, producing a partial pre-order (Figueira et al., 2005; Roy, 1991). In this method, preference of alternatives is evaluated by series of indexes, $g_{i}(a)$. In outranking methods, comparisons are stated by binary relations. Thresholds in ELECTRE III are defined as follows,

i) $A=\left\{a_{i} \mid i=1,2, \ldots, n\right\}$ a series of alternatives

ii) $g_{j}(a)=\left\{g_{j} \mid j=1,2, \ldots, n\right\}$ a series of indexes

iii) $\mathrm{K}_{\mathrm{j}}$ or $\mathrm{W}_{\mathrm{j}}$ is the weight or importance given to the criteria by decision maker by considering that total $\mathrm{K}_{\mathrm{j}}=1$.

To compare two alternatives, namely $(\mathrm{a}, \mathrm{b}) \in \mathrm{A}$ we have:

(a is strictly preferred to b) $\quad$ a P b: $\quad g(a)-g(b) \geq p$

(a is weakly preferred to b) a Q b: $\quad \mathrm{q}<\mathrm{g}(\mathrm{a})-\mathrm{g}(\mathrm{b})<\mathrm{p}$

(a is indifferent to $b$ ) $\quad a$ I b: $\quad|g(a)-g(b)| \leq q$

In addition, incomparability of $(\mathrm{R})$ occurs when there is a hesitation between $\mathrm{aPb}$ and $\mathrm{bPa}$. In multicriteria problems, when we say aSb, it means that "a is at least as well as b" or "b is not worse than a". In this way, reliability or non-reliability of a $\mathrm{S} b$ will be examined which requires to examine concordance and discordance indexes (Buchanan \& Vanderpooten, 2007; Sherris \& Quang, 2012).

\subsubsection{Concordance Index}

Concordance index indicates majority of indexes in support of this reliability.

$$
\begin{aligned}
& \mathrm{C}(\mathrm{a}, \mathrm{b})=\frac{1}{\mathrm{k}} \sum k_{j} \times C_{j}(\mathrm{a}, \mathrm{b}) \\
& \mathrm{K}=\sum_{j=1}^{r} k_{j}
\end{aligned}
$$

$\mathrm{K}_{\mathrm{j}}=$ importance coefficient (weight) for $j$ criterion and $(\mathrm{a}, \mathrm{b})=$ indicates a pair of options, which are compared together. $\mathrm{C}_{\mathrm{j}}(\mathrm{a}, \mathrm{b})=$ shows $\mathrm{q}$ accordance indices for $\mathrm{j}$ criterion, and pi and $\mathrm{q}_{\mathrm{j}}$ are indifference and preference threshold values. $\mathrm{g}_{\mathrm{j}}(\mathrm{a})=$ value of an option on $j$ criterion, and $\mathrm{C}(\mathrm{a}, \mathrm{b})$ indicates overall coordination grade (Buchanan \& Vanderpooten, 2007; Sherris \& Quang, 2012).

$$
C_{j}(a, b)=\left\{\begin{array}{cc}
1 & \text { if } g_{j}(a)+q_{j} \leq g_{j}(b) \\
0 & \text { if } g_{j}(a)+p_{j} \leq g_{j}(b) \\
\frac{p_{j}+g_{j}(b)-g_{j}(a)}{p_{j}-q_{j}} & \text { otherwise }
\end{array}\right.
$$




\subsubsection{Discordance Index}

Discordance index is a minority of indexes, which does not support $\mathrm{aS}_{\mathrm{j}} \mathrm{b}$ validity. Another threshold called Veto is defined for discordance, which is capable of completely rejecting aSb validity. If veto threshold is not defined, discordance index will be equal to Zero (Buchanan \& Vanderpooten, 2007; Sherris \& Quang, 2012).

$d_{j}(a, b)=\left\{\begin{array}{cc}1 & \text { if } g_{j}(a)+v_{j} \leq g_{j}(b) \\ 0 & \text { if } g_{j}(a)+p_{j} \leq g_{j}(b) \\ \frac{g_{j}(b)-g_{j}(a)-p_{j}}{v_{j}-p_{j}} & \text { otherwise }\end{array}\right.$

$\mathrm{V}_{\mathrm{j}}=$ veto threshold

\subsubsection{Calculation of Validity Matrix (S)}

Concordance and disconcordance amounts are obtained for each pair of $\epsilon \mathrm{A}(\mathrm{a}, \mathrm{b})$ alternatives. Then, the indexes of these two amounts are obtained to determine the combined outranking grade, which is obtained from this matrix process of reliability degree and a S b (Buchanan \& Vanderpooten, 2007; Sherris \& Quang, 2012).

$S(a, b)=\left\{\begin{array}{cc}C(a, b) & \text { if } d_{j}(a, b) \leq C(a, b) \quad \forall j \\ C(a, b) \prod_{j \in(a, b)} \frac{1-d_{j}(a, b)}{1-C(a, b)} & \text { otherwise }\end{array}\right.$

Here

$J(a, b)$ indicates those indexes in which $d_{j}(a, b) \geq C(a, b)$,

$J(a, b)=$ Compared criteria,

$a S b=$ Preference level of alternative $a$ compared with alternative $b$,

$C j(a, b)=$ Coordination index for $\mathrm{j}^{\text {th }}$ criterion,

$Q_{j}$ and $p_{j}$ are the amounts of indifference and preference, respectively,

$d_{j}(a, b)=$ Discordance index,

$\Pi$ sign $=$ Product of components.

\subsubsection{Ranking the Alternatives}

Ascending and descending pre-rankings are obtained followed by final ranking obtained by their combination; however, alternatives are arranged in descending distillation from the best alternatives to the worst. For this purpose, $\lambda$ parameter is defined (Buchanan $\&$ Vanderpooten, 2007; Sherris $\&$ Quang, 2012) as follows,

$\lambda=\max _{a, b \in A} S(a, b)$

This parameter determines the reliability amount to which only those amounts of $\mathrm{S}(\mathrm{a}, \mathrm{b})$ are close which consider that. The new $S(\lambda)$ parameter is also presented.

$$
S(\lambda)=\lambda a+B
$$

Finally, matrix $T$ is calculated: 
$T(a, b)=\left\{\begin{array}{cc}1 & S(a, b)>\lambda-S(\lambda) \\ 0 & \text { otherwise }\end{array}\right.$

Then, utility of each alternative is displayed by $\mathrm{Q}(\mathrm{a})$, which is the number of alternatives to which alternative $a$ has overcome minus the number of alternatives that have been better than $a$. In other words, $Q(a)$ is the sum of numbers existing in the line minus total sum of numbers in the columns of matrix $T$. In the descending process, total alternatives with the highest utility receive the highest ranks. In ascending rankings, the alternatives with the least utility receive the highest ranks first. (Buchanan \& Vanderpooten, 2007; Sherris \& Quang, 2012).

\section{Research Findings}

\subsection{Implementation}

SANA 7 software is used to rank the studied companies based on 6 decision making criteria using ELECTRE III technique. SANA 7 software is an Excel-based software and some of its advantages including consideration of positive and negative directions of criteria, automatic change of data related to negative direction criteria into positive direction data.

\section{Table 1}

Prioritization of Criteria by Decision Maker

\begin{tabular}{lllcccc}
\hline Criteria & EVA & ROA & ROE & Q-Tobin & EPS & P/E \\
\hline Weight & 0.405 & 0.256 & 0.17 & 0.09 & 0.0515 & 0.0275 \\
\hline
\end{tabular}

The results obtained from ranking of companies using ELECTRE III techniques together with the ranking announced by stock exchange are shown in Table 2.

Table 2

Ranking of Corporation's by ELECTRE III and Stock Exchange

\begin{tabular}{lccccccccccccccccccccc}
\hline & T & S & R & Q & P & O & N & M & L & K & J & I & H & G & F & E & D & C & B & A \\
\hline Stock Exchange & 17 & 18 & 10 & 14 & 19 & 16 & 20 & 7 & 12 & 13 & 15 & 9 & 5 & 6 & 4 & 10 & 2 & 8 & 1 & 3 \\
ELECTRE III & 20 & 8 & 2 & 18 & 13 & 15 & 7 & 17 & 4 & 5 & 19 & 12 & 16 & 6 & 10 & 14 & 11 & 9 & 3 & 1 \\
\hline
\end{tabular}

At the end, the ranking obtained by ELECTRE III technique is evaluated together with the ranking announced by TSE, which is based on liquidity criterion using Wilcoxon test and SPSS16 software.

During Wilcoxon test in SPSS 16 software environment, the ranking obtained by ELECTRE III method was compared with the ranking announced by stock exchange and a significant level (sigAsymp) of $84 \%$ was obtained, which indicates lack of any significant difference between the ranking obtained by ELECTRE III and the ranking notified by stock exchange.

\section{Conclusions}

1) Since no significant difference was found between the ranking obtained by ELECTRE III and the ranking announced by the stock exchange, this indicates that ELECTRE III is an effective and useful technique for evaluation and ranking of stock exchange companies.

2) Since 5 out of the 6 performance evaluation criteria intended by the decision maker included accounting criteria and there is no significant difference between the rankings obtained in this research and those announced by the stock exchange, this indicates that accounting criteria were considered among the most important criteria for evaluation of companies' performances despite the possible deficiencies stated for them by the researchers concerning the following issues: a) No consideration to cost of capital (Chen \& Dodd, 2001), b) Possibility of distortion and manipulation of 
profit by selecting different procedures (Stewart, 1991), c) As the prices change, the profit measured by historical money unit changes as well (Hendriksen, 1982). The results of this survey are consistent with the statements of Balsam and Lipka (1998), Lehn and Makhija (1996), Worthington and West (2004) indicating the availability of necessary information in these models and their easy calculations. This group of performance evaluation criteria has been widely used by users of financial information.

3) Following the identification of major financial criteria influencing on the decisions of shareholders in selecting share portfolio and the importance of each of them, the findings indicate that economic criteria are of the highest level of importance among different criteria, which means the attention of experts of stock exchange to variables related to profitability of companies and economic nature of their activities. Despite EVA criterion in which total capital cost is considered, the disadvantage of performance evaluation accounting systems, which only considers debt cost and the general accepted accounting procedures allows non-uniformity in measuring the profit in different companies. Furthermore, as the level of prices change, the profit measured by historical monetary unit is changed. The results are in line with the statements of Stewart (1991) and Hendriksen et al. (1982).

4) The results obtained from the ranking of companies indicate that the criteria used in this research were in line with the liquidity criteria and this confirms the fact that both accounting criteria and value-based criteria could be useful and suitable bases for investors in selecting a portfolio. What is clear is that all indexes for performance evaluation including traditional and modern techniques evaluate company's performance and assist in dynamism, growth and continuation of firms' activities. In this way use of performance evaluation criteria which is a kind of strong managerial control system can lead to optimum allocation of limited resources. These criteria should be used with an incorporation of traditional and modern indexes and other criteria without any consideration to the common classifications so that the best result is provided.

\section{References}

Balsam, S., \& Lipka, R. (1998). Share prices and alternative measures of earnings per share. Accounting Horizons, 12(3), 248.

Bausch, A., Weißenberger, B. E., \& Blome, M. (2003). Is market value-based residual income a superior performance measure compared to book value-based residual income. ebook] Giessen: university of Giessen. Available through: Giessen Giessen Electronic Library, < http://geb. unigiessen. de $>$ [Accessed 19 August 2005].

Bacidore, J. M., Boquist, J. A., Milbourn, T. T., \& Thakor, A. V. (1997). The search for the best financial performance measure. Financial Analysts Journal, 53(3), 11-20.

Buchanan, J., \& Vanderpooten, D. (2007). Ranking projects for an electricity utility using ELECTRE III. International Transactions in Operational Research,14(4), 309-323.

Chen, S., \& Dodd, J. L. (2001). Operating income, residual income and EVA ${ }^{\mathrm{TM}}$ : which metric is more value relevant?. Journal of Managerial Issues, 13(1), 65-86.

Ehrgott, M., Klamroth, K., \& Schwehm, C. (2004). An MCDM approach to portfolio optimization. European Journal of Operational Research, 155(3), 752-770.

Figueira, J., Mousseau, V., \& Roy, B. (2005). ELECTRE methods. In Multiple criteria decision analysis: State of the art surveys (pp. 133-153). Springer New York.

Figueira, J., \& Roy, B. (2002). Determining the weights of criteria in the ELECTRE type methods with a revised Simos' procedure. European Journal of Operational Research, 139(2), 317-326.

Hallerbach, W., \& Spronk, J. (1997). A multi-dimensional framework for portfolio management. In Essays in decision making (pp. 275-293). Springer Berlin Heidelberg.

Hendriksen, E. S., \& Van Breda, M. F. (1982). Accounting theory. RD Irwin.

Hurson, C., \& Zopounidis, C. (1997). On the use of multicriteria decision aid methods to portfolio selection. In Multicriteria Analysis (pp. 496-507). Springer Berlin Heidelberg. 
Hurson, C., \& Zopounidis, C. (1997). On the use of multicriteria decision aid methods to portfolio selection. In Multicriteria Analysis (pp. 496-507). Springer Berlin Heidelberg.

Johnson, R., \& Soenen, L. (2003). Indicators of successful companies.European Management Journal, 21(3), 364-369.

Khoury, N. T., Martel, J. M., \& Veilleux, M. (1993). Méthode multicritère de sélection de portefeuilles indiciels internationaux. Actualité Economique, Revue Analyse Economique, 69(1), 171-190.

Lee, W. S., Huang, A. Y., Chang, Y. Y., \& Cheng, C. M. (2011). Analysis of decision making factors for equity investment by DEMATEL and Analytic Network Process. Expert Systems with Applications, 38(7), 8375-8383.

Lehn, K., \& Makhija, A. K. (1997). EVA, accounting profits, and CEO turnover: an empirical examination, 1985-1994. Journal of applied corporate finance,10(2), 90-97.

Lipe, M. G. (1998). Individual investors' risk judgments and investment decisions: The impact of accounting and market data. Accounting, Organizations and Society, 23(7), 625-640.

Martel, J. M., Khoury, N. T., \& Bergeron, M. (1988). An application of a multicriteria approach to portfolio comparisons. Journal of the Operational Research Society, 39(7), 617-628.

Montazer, G. A., Saremi, H. Q., \& Ramezani, M. (2009). Design a new mixed expert decision aiding system using fuzzy ELECTRE III method for vendor selection. Expert Systems with Applications, 36(8), 10837-10847.

Roy, B. (1991). The outranking approach and the foundations of ELECTRE methods. Theory and decision, 31(1), 49-73.

Roy, B., \& Vanderpooten, D. (1996). The European school of MCDA: Emergence, basic features and current works. Journal of Multi-Criteria Decision Analysis, 5(1), 22-38.

Sherris, M., \& Quang, D. T. (2012). Portfolio Selection for Insurance Linked Securities: An Application of Multiple Criteria Decision Making. UNSW Australian School of Business Research Paper No. AIPAR, 4.

Shim, G. Y., Lee, S. H., \& Kim, Y. M. (2008). How investor behavioral factors influence investment satisfaction, trust in investment company, and reinvestment intention. Journal of Business Research, 61(1), 47-55.

Steward, G. B. (1991). The quest for value: a guide for senior managers. New York.

Stewart, S. (1993). Comparison of economic value added with popular accounting measures. Financial Analysts Journal, 2(2), 123-133.

Szala, A. (1990). L'Aide a la Decision en Gestion de Portefeuille. Diplome Superieur de Recherches Appliquees. Universite de Paris Dauphine.

Worthington, A. C., \& West, T. (2004). Australian evidence concerning the information content of economic value-added. Australian Journal of Management, 29(2), 201-223.

Zopounidis, C. (1995). Evaluation du risque de défaillance de l'entreprise: Méthodes et cas d'application. Economica.

Zopounidis, C. (1999). Multicriteria decision aid in financial management.European Journal of Operational Research, 119(2), 404-415. 


\section{Appendix}

Table 3

Input data in SANA7 Software

\begin{tabular}{|c|c|c|c|c|c|c|}
\hline & MAX & MAX & MAX & MAX & MAX & MIN \\
\hline & 1.EVA & 2.ROA & 3.ROE & $4 . \mathrm{O}-\mathrm{T}$ & 5.EPS & $6 . \mathrm{P} / \mathrm{E}$ \\
\hline A & 10427794 & 0.3043 & 0.41 & 1.9 & 885 & 5.425 \\
\hline B & 14046098 & 0.1759 & 0.24 & 1.87 & 390 & 8.423 \\
\hline $\mathrm{C}$ & 473327 & 0.1655 & 0.19 & 1.24 & 325 & 6.73 \\
\hline D & 455998 & 0.1453 & 0.2177 & 0.8487 & 345 & 3.527 \\
\hline $\mathrm{E}$ & 51233 & 0.129 & 0.11 & 0.98 & 173 & 8.532 \\
\hline $\mathrm{F}$ & 480233 & 0.1283 & 0.2301 & 1.36 & 353 & 7.054 \\
\hline $\mathrm{G}$ & 438968 & 0.1825 & 0.2252 & 0.8506 & 330 & 3.615 \\
\hline $\mathrm{H}$ & -83082 & 0.1073 & 0.2658 & 1.22 & 2767 & 1.172 \\
\hline I & 161389 & 0.0809 & 0.35 & 1.18 & 439 & 5.961 \\
\hline $\mathrm{J}$ & -20 & 0.0738 & 0.091 & 0.7305 & 117 & 6.632 \\
\hline $\mathrm{K}$ & 268312 & 0.1701 & 0.32 & 1.39 & 639 & 5.508 \\
\hline $\mathrm{L}$ & 211236 & 0.2339 & 0.2753 & 1.26 & 406 & 5.143 \\
\hline $\mathrm{M}$ & -85308 & 0.1815 & 0.18 & 0.7276 & 265 & 3.868 \\
\hline $\mathrm{N}$ & 78697 & 0.2211 & 0.39 & 1.13 & 787 & 3.253 \\
\hline $\mathrm{O}$ & 28630 & 0.1074 & 0.13 & 1.03 & 332 & 4.066 \\
\hline $\mathrm{P}$ & 95567 & 0.19 & 0.2172 & 0.87 & 537 & 3.857 \\
\hline Q & 219038 & 0.1043 & 0.0919 & 0.93 & 135 & 9.007 \\
\hline $\mathrm{R}$ & 2820960 & 0.2793 & 0.34 & 1.63 & 795 & 5.283 \\
\hline $\mathrm{S}$ & 72904 & 0.2312 & 0.2323 & 3.23 & 322 & 3.624 \\
\hline $\mathrm{T}$ & -373805 & -0.0259 & 0.6 & 2.6 & 1925 & 7.756 \\
\hline Weight & 0.41500 & 0.26700 & 0.16300 & 0.08400 & 0.04600 & 0.02600 \\
\hline
\end{tabular}

Table 4

Modified input data by the software

\begin{tabular}{|c|c|c|c|c|c|c|}
\hline & MAX & MAX & MAX & MAX & MAX & MAX \\
\hline & 1.EVA & 2.ROA & 3.ROE & 4.Q-T & 5.EPS & $6 . \mathrm{P} / \mathrm{E}$ \\
\hline A & 10801599 & 0.3302 & 0.41 & 1.9 & 885 & 3.582 \\
\hline B & 14419903 & 0.2018 & 0.24 & 1.87 & 390 & 0.584 \\
\hline $\mathrm{C}$ & 847132 & 0.1914 & 0.19 & 1.24 & 325 & 2.277 \\
\hline $\mathrm{D}$ & 829803 & 0.1712 & 0.2177 & 0.8487 & 345 & 5.48 \\
\hline E & 425038 & 0.1549 & 0.11 & 0.98 & 173 & 0.475 \\
\hline F & 854038 & 0.1542 & 0.2301 & 1.36 & 353 & 1.953 \\
\hline $\mathrm{G}$ & 812773 & 0.2084 & 0.2252 & 0.8506 & 330 & 5.392 \\
\hline $\mathrm{H}$ & 290723 & 0.1332 & 0.2658 & 1.22 & 2767 & 7.835 \\
\hline I & 535194 & 0.1068 & 0.35 & 1.18 & 439 & 3.046 \\
\hline $\mathrm{J}$ & 373785 & 0.0997 & 0.091 & 0.7305 & 117 & 2.375 \\
\hline K & 642117 & 0.196 & 0.32 & 1.39 & 639 & 3.499 \\
\hline $\mathrm{L}$ & 585041 & 0.2598 & 0.2753 & 1.26 & 406 & 3.864 \\
\hline M & 288497 & 0.2074 & 0.18 & 0.7276 & 265 & 5.139 \\
\hline $\mathrm{N}$ & 452502 & 0.247 & 0.39 & 1.13 & 787 & 5.754 \\
\hline $\mathrm{O}$ & 402435 & 0.1333 & 0.13 & 1.03 & 332 & 4.941 \\
\hline $\mathrm{P}$ & 469372 & 0.2159 & 0.2172 & 0.87 & 537 & 5.15 \\
\hline Q & 592843 & 0.1302 & 0.0919 & 0.93 & 135 & 0 \\
\hline $\mathrm{R}$ & 3194765 & 0.3052 & 0.34 & 1.63 & 795 & 3.724 \\
\hline S & 446709 & 0.2571 & 0.2323 & 3.23 & 322 & 5.383 \\
\hline $\mathrm{T}$ & 0 & 0 & 0.6 & 2.6 & 1925 & 1.251 \\
\hline Weight & 0.41459 & 0.26673 & 0.16284 & 0.08392 & 0.04595 & 0.02597 \\
\hline
\end{tabular}


Table 5

Matrix S obtained by SANA7 software

\begin{tabular}{|c|c|c|c|c|c|c|c|c|c|c|c|c|c|c|c|c|c|c|c|c|}
\hline & $\mathrm{A}$ & $\mathrm{B}$ & $\mathrm{C}$ & $\mathrm{D}$ & E & $\mathrm{F}$ & $\mathrm{G}$ & $\mathrm{H}$ & I & $\mathrm{J}$ & $\mathrm{K}$ & $\mathrm{L}$ & $\mathrm{M}$ & $\mathrm{N}$ & $\mathrm{O}$ & $\mathrm{P}$ & $\mathrm{O}$ & $\mathrm{R}$ & $\mathrm{S}$ & $\mathrm{T}$ \\
\hline $\bar{A}$ & 0.0000 & 0.5854 & 1.0000 & 0.9740 & 1.0000 & 1.0000 & 0.9740 & 0.9280 & 1.0000 & 1.0000 & 1.0000 & 0.9740 & 0.9740 & 0.9740 & 0.9740 & 0.9740 & 1.0000 & 0.9740 & 0.8901 & 7072 \\
\hline B & 0.4145 & 0.0000 & 0.9740 & 0.9740 & 1.0000 & 0.9740 & 0.7072 & 0.7652 & 0.7652 & 0.9740 & 0.7652 & 0.4985 & 0.7072 & 0.4985 & 0.9740 & 0.6613 & 1.0000 & 0.4985 & 0.6233 & 0.6813 \\
\hline C & 0.0000 & 0.0259 & 0.0000 & 0.7652 & 1.0000 & 0.2927 & 0.4985 & 0.7652 & 0.7652 & 0.9740 & 0.4145 & 0.4145 & 0.7072 & 0.4985 & 0.9280 & 0.4985 & 1.0000 & 0.0000 & 0.4605 & 0.7072 \\
\hline D & 0.0259 & 0.0259 & 0.2347 & 0.0000 & 0.9160 & 0.2927 & 0.4865 & 0.6813 & 0.7072 & 1.0000 & 0.4405 & 0.4405 & 0.7332 & 0.4145 & 0.9160 & 0.6034 & 0.9160 & 0.0259 & 0.4865 & 0.7072 \\
\hline E & 0.0000 & 0.0000 & 0.0000 & 0.0839 & 0.0000 & 0.2667 & 0.0839 & 0.6813 & 0.2667 & 0.9740 & 0.0000 & 0.0000 & 0.4985 & 0.0000 & 0.6813 & 0.0839 & 0.5854 & 0.0000 & 0.0000 & 0.6813 \\
\hline F & 0.0000 & 0.0259 & 0.7072 & 0.7072 & 0.7332 & 0.0000 & 0.7072 & 0.7652 & 0.7652 & 0.9740 & 0.4145 & 0.4985 & 0.7072 & 0.4985 & 0.9740 & 0.6613 & 1.0000 & 0.0000 & 0.4605 & 0.7072 \\
\hline G & 0.0259 & 0.2927 & 0.5015 & 0.5134 & 0.9160 & 0.2927 & 0.0000 & 0.6813 & 0.7072 & 1.0000 & 0.7072 & 0.4405 & 1.0000 & 0.4145 & 0.8701 & 0.6034 & 0.9160 & 0.0259 & 0.4865 & 0.7072 \\
\hline $\mathrm{H}$ & 0.0719 & 0.2347 & 0.2347 & 0.3186 & 0.3186 & 0.2347 & 0.3186 & 0.0000 & 0.4225 & 0.5854 & 0.0719 & 0.0719 & 0.7332 & 0.1558 & 0.3186 & 0.3186 & 0.5854 & 0.0719 & 0.2347 & 0.7532 \\
\hline I & 0.0000 & 0.2347 & 0.2347 & 0.2927 & 0.7332 & 0.2347 & 0.2927 & 0.5774 & 0.0000 & 1.0000 & 0.1628 & 0.2087 & 0.7072 & 0.4985 & 0.7072 & 0.6613 & 0.3186 & 0.1628 & 0.6233 & 0.7072 \\
\hline $\mathrm{J}$ & 0.0000 & 0.0259 & 0.0259 & 0.0000 & 0.0259 & 0.0259 & 0.0000 & 0.4145 & 0.0000 & 0.0000 & 0.0000 & 0.0000 & 0.4985 & 0.0000 & 0.0000 & 0.0000 & 0.0259 & 0.0000 & 0.0000 & 0.7072 \\
\hline K & 0.0000 & 0.2347 & 0.5854 & 0.5594 & 1.0000 & 0.5854 & 0.2927 & 0.9280 & 0.8371 & 1.0000 & 0.0000 & 0.7072 & 0.7072 & 0.4985 & 0.9740 & 0.7072 & 1.0000 & 0.0000 & 0.6233 & 0.7072 \\
\hline L & 0.0259 & 0.5015 & 0.5854 & 0.5594 & 1.0000 & 0.5015 & 0.5594 & 0.9280 & 0.7912 & 1.0000 & 0.2927 & 0.0000 & 0.9740 & 0.7652 & 0.9740 & 0.9280 & 0.5854 & 0.0259 & 0.8901 & 0.7072 \\
\hline M & 0.0259 & 0.2927 & 0.2927 & 0.2667 & 0.5015 & 0.2927 & 0.0000 & 0.2667 & 0.2927 & 0.5015 & 0.2927 & 0.0259 & 0.0000 & 0.0000 & 0.4555 & 0.0000 & 0.5015 & 0.0259 & 0.0000 & 0.7072 \\
\hline $\mathrm{N}$ & 0.0259 & 0.5015 & 0.5015 & 0.5854 & 1.0000 & 0.5015 & 0.5854 & 0.8441 & 0.5015 & 1.0000 & 0.5015 & 0.2347 & 1.0000 & 0.0000 & 1.0000 & 0.5854 & 0.5854 & 0.1888 & 0.6493 & 0.7072 \\
\hline $\mathrm{O}$ & 0.0259 & 0.0259 & 0.0719 & 0.0839 & 0.3186 & 0.0259 & 0.1298 & 0.6813 & 0.2927 & 1.0000 & 0.0259 & 0.0259 & 0.5444 & 0.0000 & 0.0000 & 0.0839 & 0.5854 & 0.0259 & 0.0459 & 0.7072 \\
\hline $\mathrm{P}$ & 0.0259 & 0.3386 & 0.5015 & 0.3966 & 0.9160 & 0.3386 & 0.3966 & 0.6813 & 0.3386 & 1.0000 & 0.2927 & 0.0719 & 1.0000 & 0.4145 & 0.9160 & 0.0000 & 0.5015 & 0.0259 & 0.4605 & 0.7072 \\
\hline $\mathrm{Q}$ & 0.0000 & 0.0000 & 0.0000 & 0.0839 & 0.4145 & 0.0000 & 0.0839 & 0.4145 & 0.6813 & 0.9740 & 0.0000 & 0.4145 & 0.4985 & 0.4145 & 0.4145 & 0.4985 & 0.0000 & 0.0000 & 0.4145 & 0.6813 \\
\hline $\mathrm{R}$ & 0.0259 & 0.5015 & 1.0000 & 0.9740 & 1.0000 & 1.0000 & 0.9740 & 0.9280 & 0.8371 & 1.0000 & 1.0000 & 0.9740 & 0.9740 & 0.8111 & 0.9740 & 0.9740 & 1.0000 & 0.0000 & 0.8901 & 0.7072 \\
\hline $\mathrm{S}$ & 0.1098 & 0.3766 & 0.5394 & 0.5134 & 1.0000 & 0.5394 & 0.5134 & 0.7652 & 0.3766 & 1.0000 & 0.3766 & 0.1098 & 1.0000 & 0.3506 & 0.9540 & 0.5394 & 0.5854 & 0.1098 & 0.0000 & 0.7912 \\
\hline $\mathrm{T}$ & 0.2927 & 0.3186 & 0.2927 & 0.2927 & 0.3186 & 0.2927 & 0.2927 & 0.2467 & 0.2927 & 0.2927 & 0.2927 & 0.2927 & 0.2927 & 0.2927 & 0.2927 & 0.2927 & 0.3186 & 0.2927 & 0.2087 & 0.0000 \\
\hline
\end{tabular}

